\title{
Magnitude and variability of land evaporation and its components at the global scale
}

\author{
D. G. Miralles ${ }^{1}$, R. A. M. De Jeu ${ }^{1}$, J. H. Gash ${ }^{1}$, T. R. H. Holmes ${ }^{1,2}$, and A. J. Dolman ${ }^{1}$ \\ ${ }^{1}$ Department of Hydrology, VU University, Amsterdam, The Netherlands \\ ${ }^{2}$ Hydrology and Remote Sensing Lab, USDA-ARS, Beltsville, MD, USA \\ Received: 10 December 2010 - Published in Hydrol. Earth Syst. Sci. Discuss.: 3 January 2011 \\ Revised: 11 March 2011 - Accepted: 14 March 2011 - Published: 17 March 2011
}

\begin{abstract}
A process-based methodology is applied to estimate land-surface evaporation from multi-satellite information. GLEAM (Global Land-surface Evaporation: the Amsterdam Methodology) combines a wide range of remotelysensed observations to derive daily actual evaporation and its different components. Soil water stress conditions are defined from a root-zone profile of soil moisture and used to estimate transpiration based on a Priestley and Taylor equation. The methodology also derives evaporationfrom bare soil and snow sublimation. Tall vegetation rainfall interception is independently estimated by means of the Gash analytical model. Here, GLEAM is applied daily, at global scale and a quarter degree resolution. Triple collocation is used to calculate the error structure of the evaporation estimates and test the relative merits of two different precipitation inputs. The spatial distribution of evaporation - and its different components - is analysed to understand the relative importance of each component over different ecosystems. Annual land evaporation is estimated as $67.9 \times 10^{3} \mathrm{~km}^{3}, 80 \%$ corresponding to transpiration, $11 \%$ to interception loss, $7 \%$ to bare soil evaporation and $2 \%$ snow sublimation. Results show that rainfall interception plays an important role in the partition of precipitation into evaporation and water available for runoff at a continental scale. This study gives insights into the relative importance of precipitation and net radiation in driving evaporation, and how the seasonal influence of these controls varies over different regions. Precipitation is recognised as an important factor driving evaporation, not only in areas that have limited soil water availability, but also in areas of high rainfall interception and low available energy.
\end{abstract}

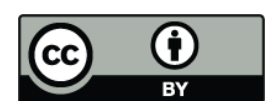

Correspondence to: D. G. Miralles (diego.miralles@falw.vu.nl)

\section{Introduction}

Despite the importance of latent heat flux as the link between water, carbon and energy cycles, land-surface evaporation remains one of the most uncertain terms in the world's water balance (Dolman and de Jeu, 2010). Estimates of evaporation from land surface models and Global Circulation Models (GCMs) differ greatly both in their global numbers (see Dirmeyer et al., 2006; Lim and Roderick, 2009) and their spatial distribution (Jiménez et al., 2009). This creates the need for observation-based evaporation benchmark datasets to evaluate GCM performance (Blyth et al., 2009). Such datasets would help GCM developers to improve their evaporation schemes and consequently their model predictions of future climate.

Jung et al. (2009) presented an approach to upscale eddycovariance measurements of latent heat flux and produce observation-based global fields of evaporation at monthly timescale. Complementary, satellite observations - able to measure the spatial and temporal variation in the main drivers of evaporation - also contribute a powerful alternative to fulfilling the need for accurate global estimates of evaporation. Such estimates have been derived from remote sensing information previously (Choudhury, 1998; Mu et al., 2007; Fisher et al., 2008; Zhang et al., 2010). These studies show that global methodologies require: (a) estimating evaporation at the appropriate temporal and spatial resolution, (b) specifically accounting for soil moisture and its coupling to plant transpiration, and (c) treating forest rainfall interception as an individual process (see Jiménez et al., 2011). Here we satisfy these requirements by using the approach described by Miralles et al. (2011) at a global scale. The methodology, named GLEAM (Global Land-surface Evaporation: the Amsterdam Methodology), is based on the Priestley and Taylor (PT) evaporation formula and the Gash analytical model

Published by Copernicus Publications on behalf of the European Geosciences Union. 


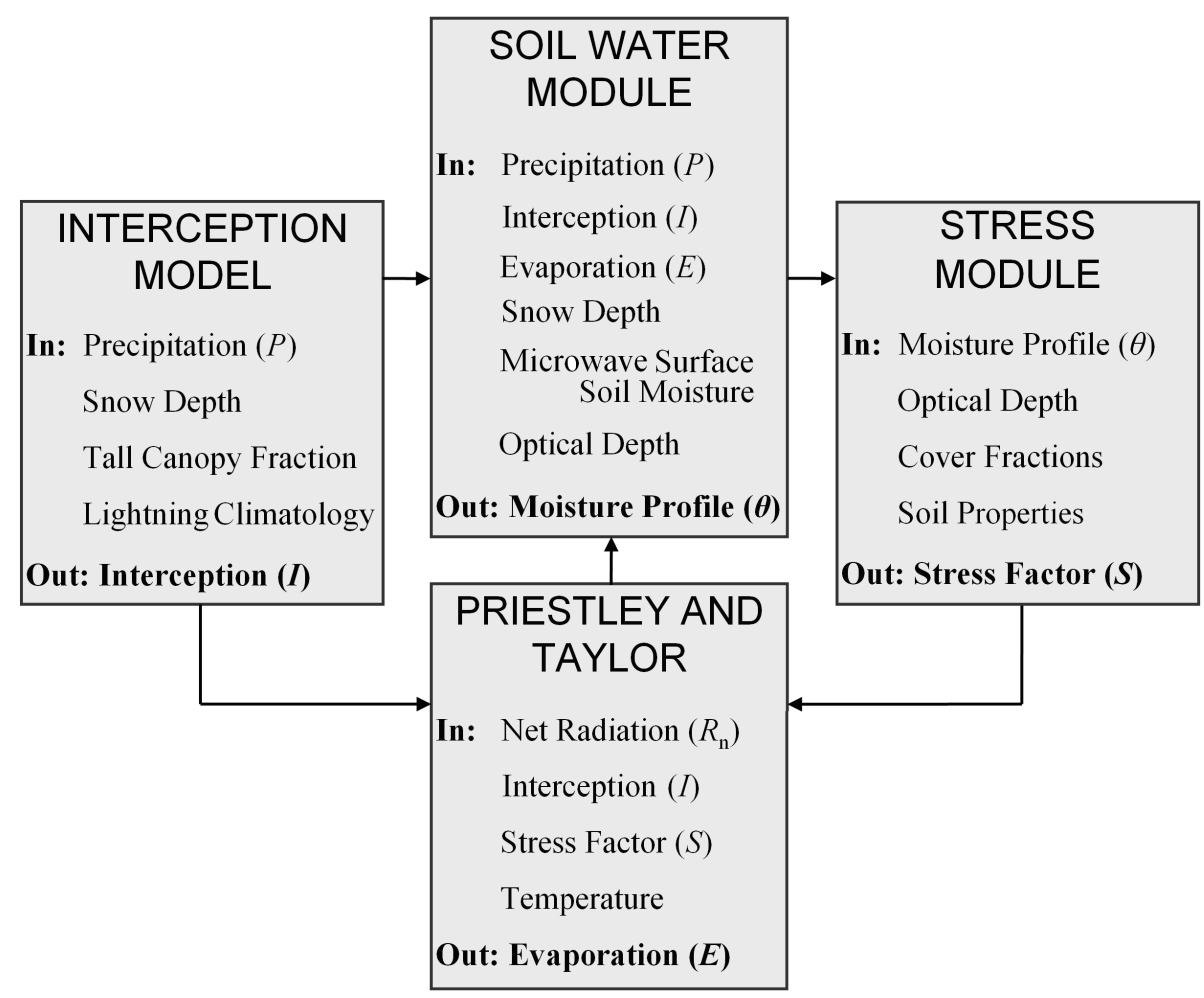

Fig. 1. Schematic overview of GLEAM (adapted from Miralles et al., 2011).

of forest rainfall interception (Gash, 1979; Valente et al., 1997).

GLEAM uses a broad range of independent remotelysensed observations as a basis for estimating daily actual evaporation (and its different components) at a quarterdegree spatial resolution. The approach is based on the parameterization of physical processes and although it contains some empirical parameters these have been derived from the results of separate field studies. The evaporation product has been successfully validated at site level over different vegetation and climate conditions using in situ observations from 43 stations of the FLUXNET global network of micrometeorological flux measurements (see Miralles et al., 2011). The extensive use of observational data, the coupling between evaporation and soil moisture conditions and the separate estimation of rainfall interception allow application of the methodology in land-atmosphere feedback studies and tests of GCM performance.

Here, triple collocation (TC) is used to map the error of the evaporation estimates following the methodology in Miralles et al. (2010a). GLEAM is then applied at a watershed scale to validate the estimated long-term partitioning of incoming precipitation $(P)$ into evaporation $(E)$ and water available for runoff $(P-E)$ using observations of river discharge from the Global Runoff Data Centre (GRDC). The methodology is finally applied at a global scale to study the global distribution of land evaporation and its different components. The role of rainfall interception and soil moisture on both the long-term partitioning of precipitation, and the seasonal distribution of the main drivers of evaporation (i.e. net radiation and precipitation), are analysed in detailed.

\section{Methodology}

\subsection{GLEAM}

The model is driven by a large set of remote sensing observations from different satellites (see Miralles et al., 2011, for a detailed description of the different input datasets and full details of the methodology). GLEAM produces daily estimates of land evaporation at a $0.25^{\circ}$ spatial resolution. It is structured in four interconnected units (see Fig. 1): (a) the interception model, (b) the soil water module, (c) the stress module, and (d) the PT module. The scheme is independently formulated for three land surface types with specific physical characteristics: (a) land covered by tall canopies, (b) land covered by short vegetation, and (c) bare soil.

The interception model in GLEAM is based on the revised version of Gash's analytical model (Valente et al., 1997). It calculates daily fields of global tall canopy rainfall interception at $0.25^{\circ}$ resolution $(I)$ using remotely-sensed observations of precipitation $(P)$ and forest cover. The interception 
component of GLEAM is described in detail by Miralles et al. (2010b).

The soil water module consists of a multilayer bucket model driven by $P$ and calculating soil moisture for different layers within the root-zone. Satellite-measured surface soil moisture is assimilated into the first layer of the profile by means of a Kalman filter. The Kalman filter is based on the uncertainty of soil moisture observations, which is calculated using satellite-derived vegetation optical depth (the higher the optical depth, the higher the uncertainty in surface soil moisture - see De Jeu et al., 2008). Optimised estimates of soil moisture $(\theta)$ are subsequently translated into estimates of evaporative stress represented by a factor $(S)$, ranging from 0 (maximum stress) to 1 (no stress). PT estimates of potential evaporation are multiplied by $S$ to estimate plant transpiration (in vegetated cover) and bare soil evaporation. The final estimate of actual evaporation for each pixel is the result of aggregating the fluxes from the three different land cover types (tall canopy interception loss, tall canopy transpiration, short vegetation transpiration, bare soil evaporation) weighted by the percentage of each cover type within the pixel. In pixels covered by ice and snow, $E$ is independently calculated by adapting the PT equation to estimate sublimation as described by Murphy and Koop (2005).

\subsection{Error analysis}

A traditional way to estimate the uncertainty of model outputs is through error propagation studies. These studies account for the sensitivity of the output to uncertainties in the input data but do not give information on the quality of the model itself. Triple collocation (TC - Stoffelen, 1998; Scipal et al., 2008), however, allows the estimation of the entire error structure of the estimates of a model. This is done by simultaneously inter-comparing the product to two other datasets that observe the same physical phenomenon and present uncorrelated errors. Here, we are not only interested in the sensitivity of GLEAM estimates to errors in the set of inputs, but also in the uncertainties introduced by the parameterization of the physical processes within the methodology. Consequently, an error analyses based on TC has been undertaken to evaluate the evaporation product.

Requirements for the application of TC are: (a) the three datasets must refer to the same physical phenomenon, (b) the number of triplets has to be large (i.e. sufficient time steps in which the three datasets report an estimate), and (c) errors of the different datasets must be uncorrelated. If these three requisites are fulfilled the estimated errors of a single product are not sensitive to the choice of the two other datasets (see Dorigo et al., 2010).

In order to meet the requirement of uncorrelated errors the products need to be mutually independent. To perform the TC-based evaluation of GLEAM, two (a priori) independent global daily evaporation datasets were selected: (a) the Princeton University product (Sheffield et al., 2010), and (b) the Modern Era Retrospective-analysis for Research and Applications (MERRA) product. The Princeton University product is based on the application of a modified PenmanMonteith equation driven by a collection of satellite data. MERRA evaporation is a reanalysis product from NASA that uses the Goddard Earth Observing System Data Assimilation System (GEOS-5 DAS - Bosilovich, 2008).

The TC analysis presented here is limited to the spatial domain and the period (2003-2006) in which the three selected products overlap. Ideally, an infinite number of common observations is required in the application of TC to obtain unbiased results. However, statistical tests revealed that a minimum number of 100 triplets is sufficient to allow the application of the method (Scipal et al., 2008).

A disadvantage of TC is that it does not retrieve any information about biases. Consequently - and in order to ease the interpretation of the results - the analyses presented here are based on characterising the error of the anomalies of evaporation as calculated relative to a seasonally-varying climatology. Therefore the feature of GLEAM that is evaluated in this study is its skill in representing short-term changes in evaporation (e.g. after rainfall events), and how that skill changes from region to region. This error analysis follows closely the methodology presented in Miralles et al. (2010a) and Dorigo et al. (2010).

For each pixel, the three datasets are decomposed into climatology mean and anomaly components:

$E_{i}=E_{i}^{\prime}+\langle E\rangle_{D(i)}^{N}$,

where $\langle E\rangle_{D(i)}^{N}$ is the climatological expectation for landsurface evaporation at the day-of-year $(D)$ associated with time step $i$, and $E_{i}^{\prime}$ is the actual anomaly relative to this expectation. Values of $\langle E\rangle_{D(i)}^{N}$ are calculated using a moving window averaging of multi-year data with a window size of 31 days centered on $D$.

Subsequently, the time series of anomalies of the three products need to be scaled to the same dynamic range. This scaling is done by first selecting one of the datasets as the reference. Then the time series of the other two are normalised at every pixel to match the standard deviation of the time series of the reference one. To retrieve the errors within the dynamic range of GLEAM the dataset selected as reference must be GLEAM. Note that the choice of the reference dataset does not influence the relative magnitude of the errors of the three products at a given pixel.

TC assumes a linear relation between the three independent estimates of a physical variable and the hypothetical true value (Stoffelen, 1998). In our case the time series of anomalies of the three evaporation products ( $E_{\mathrm{G}}^{\prime}$ for GLEAM, $E_{\mathrm{PU}}^{\prime}$ for the Princeton University product and $E_{\mathrm{M}}^{\prime}$ for MERRA) can be expressed as a function of the hypothetical true evaporation anomalies $\left(E_{\mathrm{TRUE}}^{\prime}\right)$ :

$E_{\mathrm{G}}^{\prime}=E_{\mathrm{TRUE}}^{\prime}+\epsilon_{\mathrm{G}}$, 
Table 1. GRDC stations used in the comparison of $P-E$ and observed annual river runoff $(Q)$. Results correspond to the period $2003-2006$.

\begin{tabular}{|c|c|c|c|c|c|c|c|c|c|}
\hline \multirow[t]{2}{*}{ River } & \multicolumn{3}{|c|}{ Location of the station } & \multirow[t]{2}{*}{$\begin{array}{r}\text { Area } \\
\left(10^{3} \mathrm{~km}^{2}\right)\end{array}$} & \multirow[t]{2}{*}{$\begin{array}{r}Q \\
(\mathrm{~mm})\end{array}$} & \multicolumn{2}{|c|}{$\begin{array}{l}P-E \\
(\mathrm{~mm})\end{array}$} & \multicolumn{2}{|c|}{$\begin{array}{c}E \\
(\mathrm{~mm})\end{array}$} \\
\hline & Lat (deg) & Long (deg) & Country & & & CMORPH & GPCP & CMORPH & GPCP \\
\hline Alabama & 7.80 & 6.77 & USA & 55.6 & 581 & 661 & 654 & 884 & 892 \\
\hline Apalachicola & 29.95 & -85.02 & USA & 49.7 & 443 & 515 & 596 & 895 & 910 \\
\hline Arkansas & 34.79 & -92.36 & USA & 409.3 & 83 & 405 & 115 & 735 & 647 \\
\hline Columbia & 46.18 & -123.18 & USA & 665.4 & 284 & 104 & 209 & 467 & 463 \\
\hline Danube & 45.22 & 28.72 & Romania & 807.0 & 296 & 286 & 455 & 438 & 457 \\
\hline Elbe & 53.23 & 10.89 & Germany & 132.0 & 151 & 216 & 450 & 321 & 347 \\
\hline Fraser & 49.38 & -121.45 & Canada & 217.0 & 361 & 194 & 369 & 468 & 514 \\
\hline Glomma & 59.61 & 11.12 & Norway & 40.5 & 501 & 646 & 646 & 296 & 295 \\
\hline Liard & 61.75 & -121.22 & Canada & 275.0 & 284 & 136 & 160 & 380 & 390 \\
\hline Mackenzie & 67.46 & -133.74 & Canada & 1660.0 & 177 & 83 & 97 & 329 & 344 \\
\hline Mississippi & 37.22 & -89.46 & USA & 1847.2 & 81 & 369 & 199 & 523 & 487 \\
\hline Missouri & 38.71 & -91.44 & USA & 1357.7 & 37 & 322 & 120 & 521 & 468 \\
\hline Nelson & 56.40 & -94.37 & Canada & 1060.0 & 105 & 136 & 156 & 386 & 414 \\
\hline Niger & 7.80 & 6.77 & Nigeria & 1331.6 & 125 & 381 & 156 & 368 & 327 \\
\hline Ohio & 38.28 & -85.80 & USA & 236.1 & 570 & 486 & 622 & 634 & 649 \\
\hline Rhine & 51.84 & 6.11 & Netherlands & 160.8 & 378 & 253 & 520 & 408 & 440 \\
\hline St. Lawrence & 45.42 & -73.62 & Canada & 959.1 & 265 & 212 & 478 & 492 & 546 \\
\hline Snake & 46.10 & -116.98 & USA & 240.8 & 107 & 90 & 70 & 454 & 377 \\
\hline Susquehanna & 39.66 & -76.18 & USA & 70.2 & 697 & 421 & 761 & 579 & 630 \\
\hline Tanana & 64.57 & -149.09 & USA & 66.3 & 346 & 251 & 251 & 314 & 314 \\
\hline Tennessee & 35.23 & -88.26 & USA & 85.8 & 822 & 820 & 670 & 793 & 791 \\
\hline Tombigbee & 31.76 & -88.13 & USA & 47.7 & 641 & 712 & 566 & 929 & 932 \\
\hline Wabash & 38.40 & -87.75 & USA & 74.2 & 424 & 628 & 691 & 555 & 559 \\
\hline Yukon & 61.93 & -162.88 & USA & 831.4 & 254 & 178 & 179 & 314 & 314 \\
\hline
\end{tabular}

$E_{\mathrm{PU}}^{\prime}=E_{\mathrm{TRUE}}^{\prime}+\epsilon_{\mathrm{PU}}$,

$E_{\mathrm{M}}^{\prime}=E_{\mathrm{TRUE}}^{\prime}+\epsilon_{\mathrm{M}}$,

where $\epsilon_{\mathrm{G}}, \epsilon_{\mathrm{PU}}$ and $\epsilon_{\mathrm{M}}$ are the residual errors relative to $E_{\text {TRUE }}^{\prime}$. Subtracting Eqs. (3) and (4) from Eq. (2) leads to

$E_{\mathrm{G}}^{\prime}-E_{\mathrm{PU}}^{\prime}=\epsilon_{\mathrm{G}}-\epsilon_{\mathrm{PU}}$

$E_{\mathrm{G}}^{\prime}-E_{\mathrm{M}}^{\prime}=\epsilon_{\mathrm{G}}-\epsilon_{\mathrm{M}}$.

Multiplying Eqs. (5) and (6) and taking the average in time (indicated by " $\langle-\rangle$ ") leads to

$$
\begin{aligned}
\left\langle\left( E_{\mathrm{G}}^{\prime}-\right.\right. & \left.\left.E_{\mathrm{PU}}^{\prime}\right)\left(E_{\mathrm{G}}^{\prime}-E_{\mathrm{M}}^{\prime}\right)\right\rangle \\
& =\left\langle\epsilon_{\mathrm{G}}^{2}\right\rangle-\left\langle\epsilon_{\mathrm{G}} \epsilon_{\mathrm{PU}}\right\rangle-\left\langle\epsilon_{\mathrm{G}} \epsilon_{\mathrm{M}}\right\rangle+\left\langle\epsilon_{\mathrm{PU}} \epsilon_{\mathrm{M}}\right\rangle .
\end{aligned}
$$

If the errors of the three datasets are uncorrelated the residual covariances can be assumed to be zero. Therefore Eq. (7) can be expressed as

$$
\left\langle\left(E_{\mathrm{G}}^{\prime}-E_{\mathrm{PU}}^{\prime}\right)\left(E_{\mathrm{G}}^{\prime}-E_{\mathrm{M}}^{\prime}\right)\right\rangle=\left\langle\epsilon_{\mathrm{G}}^{2}\right\rangle \text {. }
$$

The root mean square error (RMSE) of the GLEAMestimated evaporation anomalies will therefore be

$$
\operatorname{RMSE}\left(E_{\mathrm{G}}^{\prime}, E_{\mathrm{TRUE}}^{\prime}\right)=\sqrt{\left\langle\left(E_{\mathrm{G}}^{\prime}-E_{\mathrm{PU}}^{\prime}\right)\left(E_{\mathrm{G}}^{\prime}-E_{\mathrm{M}}^{\prime}\right)\right\rangle} \text {. }
$$

The results of this TC error analysis are presented in Sect. 4.1.

\section{Validation using river discharge}

This validation at basin-scale of GLEAM evaporation estimates uses river discharge measurements from the Global Runoff Data Centre (GRDC) in Koblenz, Germany. It is complementary to the validations of the independent modules described by Miralles et al. 2010b, 2011).

The study covers a period of 4 years (2003-2006). Cumulative GLEAM estimates of $P-E$ at 24 catchments are compared to observations of river runoff; the description of the river basins is presented in Table 1. Catchments were selected according to the availability of GRDC data during the complete study period and only rivers with an average annual discharge larger than $20 \mathrm{~km}^{3}$ were considered for the study.

Estimates of $P$ used in GLEAM (both in the interception model and the soil moisture module) are normally derived from the Climate Prediction Center morphing technique precipitation product (CMORPH - Joyce et al., 2004). This precipitation product is based only on satellite observations and has a high spatial resolution $\left(0.07^{\circ}\right)$. Previous studies have shown that CMORPH is in better agreement with in situ observations than the majority of existing precipitation products (e.g. Ebert et al., 2007). However CMORPH presents two practical disadvantages when applied in GLEAM: (a) its 
spatial domain $\left(60^{\circ} \mathrm{N}-60^{\circ} \mathrm{S}\right)$ does not cover the entire globe, and (b) precipitation is severely underestimated at higher latitudes during winter time (see Zeweldi and Gebremichael, 2009). Consequently, the $1^{\circ}$ resolution Global Precipitation Climatology Project (GPCP-1DD) product (Huffman et al., 2001) is used in GLEAM outside the CMORPH domain and when the temperature drops below $0{ }^{\circ} \mathrm{C}$.

Due to the obvious sensitivity of the $P-E$ estimates to uncertainties in $P$, this validation study is repeated using exclusively GPCP-1DD as $P$. Note that the choice of precipitation product implicitly affects the calculation of $E$ in GLEAM. However, the sensitivity of $P-E$ estimates to $P$ will be higher than the sensitivity of $E$ estimates to $P$ (this can also be noted in Table 1).

Figure 2 shows the results of the comparison between GLEAM catchment estimates of $P-E$ and river runoff measurements from the 24 rivers for the period 20032006. The figure shows the statistics of the correlation when the methodology is run with CMORPH $(R=0.71$, bias $=20.4 \mathrm{~mm} \mathrm{yr}^{-1}$ ) and when it is run with GPCP-1DD $\left(R=0.85\right.$, bias $\left.=46.5 \mathrm{~mm} \mathrm{yr}^{-1}\right)$. The higher correlation coefficient found for the GPCP-based $P-E$ estimates can be explained by the high positive bias of the CMORPH-based $P-E$ estimates in the rivers of central United States (see Table 1). This is in agreement with the findings of Tian et al. (2007), who reported a clear overestimation of CMORPH rainfall during the warm season in this area. This hypothesis is further analysed in Sect. 4.1.

The correlation in Fig. 2 depends on the validity of three assumptions: (a) the entire volume of river water extracted for human use returns to the river, (b) the catchment is watertight, and (c) both the lag-time between a rainfall peak in the watershed and the discharge peak in the measuring station, and the long-term change in soil water storage, can be neglected by considering a relatively long (4 year) period. Moreover, as GLEAM is not a tuned or calibrated hydrological model, Fig. 2 should be interpreted with a consideration of the magnitude and different origins of the various uncertainties. Because river discharge estimates are usually derived from a stage-discharge rating curve, they include the errors in the measurements of river height and in the discharge data used to calibrate the rating curve, as well as the errors from the interpolation and extrapolation due to changes in river bed roughness, hysteresis effects, etc (see Di Baldassarre and Montanari, 2009). On top of those, the volumes of $Q$ are also affected by the uncertainties in the estimation of the discharge-contributing area (given that the observations are presented in $\mathrm{mm}$ ). On the vertical axes, the uncertainty in $P-E$ estimates will result from the uncertainty associated with the precipitation product and with GLEAM estimates of land evaporation. The later include the errors in the satellite data used to drive GLEAM (including therefore the uncertainties in $P$ as well), the scaling of those to the desired $0.25^{\circ}$ resolution, and the model structure itself (see Miralles et al., 2011).

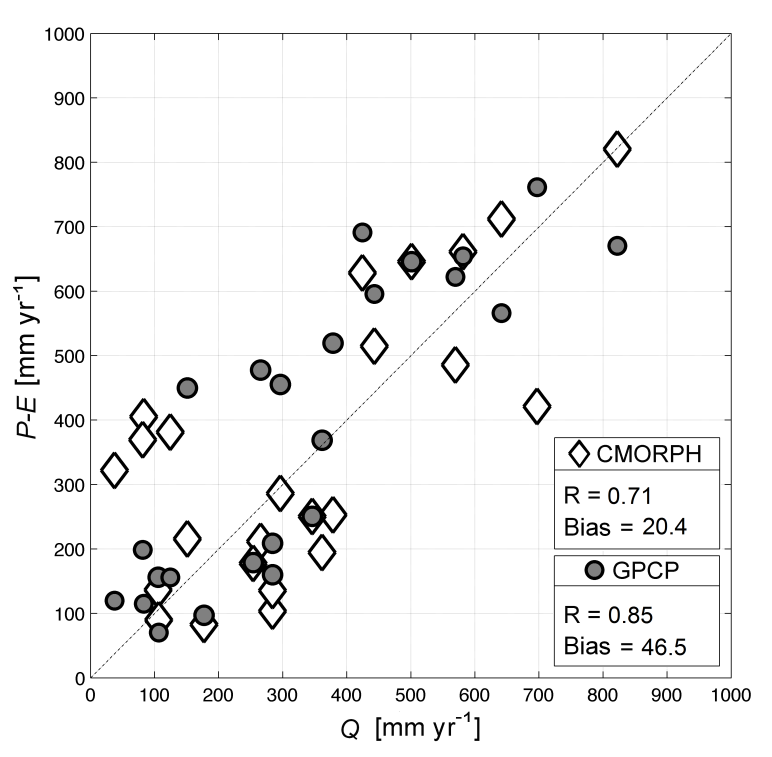

Fig. 2. GLEAM estimates of $P-E$ are compared to the runoff $(Q)$ from 24 different catchments for the period 2003-2006. Correlation coefficients $(R)$ and mean bias errors (bias) are listed for both the validation exercise using GPCP and the one using CMORPH (gapfilled with GPCP as explained in Sect. 3).

Despite all the possible sources of uncertainty a level of correlation remains as seen in Fig. 2. Furthermore, the $P-E$ estimates are of the right order of magnitude and overall lack a systematic bias relative to the one-to-one line. A global analysis of the spatial distribution of $P-E$ estimates is presented in Sect. 4.2; as in previous applications of GLEAM (i.e. Miralles et al., 2010b, 2011), the CMORPH-based $P$ is chosen for the global run of the methodology. This choice is mainly justified by the better resolution of CMORPH compared to GPCP-1DD and the overall better performance of the methodology when CMORPH is applied as reported by the results of the error analyses in Sect. 4.1.

\section{Results}

\subsection{Error analysis}

Figure 3a presents the map of the absolute error of GLEAM evaporation anomalies as calculated through Eq. (9) - the RMSE is presented in units of $\mathrm{mm} \mathrm{day}^{-1}$. The Amazon delta presents the largest errors, probably because of the large volumes of open water and their negative effect on microwave observations. High absolute errors in the rest of Amazonia and south-eastern Asia partly respond to the larger variance of the anomalies in those regions.

The quality of the product seems to be generally higher in Europe than in North America. As mentioned in Sect. 3, the low performance of CMORPH over central United States has been reported in the past (see Tian et al., 2007). To test if 

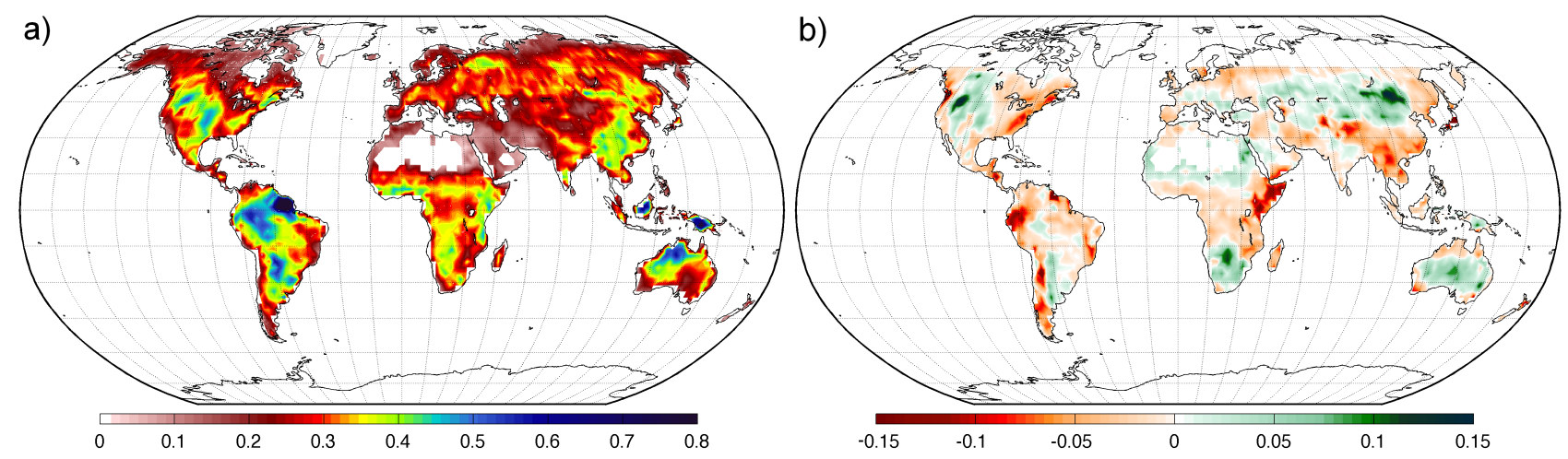

Fig. 3. Results of the triple collocation error analyses: (a) absolute error of the evaporation anomalies of GLEAM expressed as RMSE, (b) difference between the RMSE of the evaporation anomalies of GLEAM when it is run with CMORPH and when it is run with GPCP1DD (red colour represents the areas where using CMORPH improves the evaporation product). Units are mm day ${ }^{-1}$.

the high errors of GLEAM in the Great Plains respond to uncertainties in CMORPH, the analysis is repeated using only GPCP-1DD as input of the model. Figure $3 \mathrm{~b}$ presents the difference between the absolute error of GLEAM $E$ anomalies when the methodology is run with CMORPH and when it is run with GPCP-1DD only (in units of $\mathrm{mm} \mathrm{day}^{-1}$ ). It can be noted that applying GPCP-1DD improves the evaporation estimates not only over central North America but also around Mongolia, South Africa and the Australian desert. However, Fig. $3 b$ also shows higher quality for the CMORPHdriven evaporation product in the majority $(63 \%)$ of the domain common to both precipitation products $\left(60^{\circ} \mathrm{N}-60^{\circ} \mathrm{S}\right)$. The improvement is significant over the east coast of North America, west coast of South America, Horn of Africa and China. Overall the application of CMORPH leads to better evaporation estimates in all the large regions with complex topography (except for the Rocky Mountains); this finding is in agreement with previous precipitation inter-product comparisons over complex terrains (e.g. Dinku et al., 2007; Hirpa et al., 2009). This type of information about the spatial distribution of GLEAM errors can be used to selectively pick the inputs that allow a better performance of the model over each region. Notice again that bias errors are not detected by a TC analyses.

The rationale of these three approaches is fundamentally different and the assumption of uncorrelated errors appears therefore justified. However, it may be argued that some degree of interdependence exists between the Princeton University product and GLEAM due to the relation between the inputs of net radiation in each of the two models. GLEAM uses the NASA/GEWEX Surface Radiation Budget (SRB) net radiation (Stackhouse et al., 2004); the Princeton University product is run with the International Satellite Cloud Climatology Project (ISCCP) net radiation (Zhang et al., 2004). Like ISCCP net radiation, SRB is also based on ISCCP cloud products. However, SRB net radiation uses different ancillary data sources and radiative transfer codes. Both datasets still present fundamental differences (Zhang et al., 2007; Lin et al., 2008). In addition, the level of agreement between the two is lower at daily timescales (see Troy and Wood, 2009); in this sense the extraction of the seasonally-varying climatology in this exercise will make their errors more uncorrelated. Moreover, if this source of dependency was large enough to preclude the TC application, areas in which evaporation estimates are highly dependent on net radiation (see Sect. 4.2.3 for the global distribution of those areas) would be likely to present lower values of TC-calculated RMSE; this pattern is not indicated by Fig. 3. Finally it is worth mentioning that this potential dependency would not affect the results presented in Fig. 3b.

\subsection{Global application}

The methodology has been applied globally for the period 2003-2007 using the satellite data products listed by Miralles et al. (2011) as driving data. Results are analysed in terms of the magnitude of evaporation and its separate components at a continental scale and the range of variation of the different fluxes over the Earth's ecosystems. Special emphasis is given to the role of interception loss in the long-term recycling of land precipitation and its repercussions on runoff generation. The daily time-resolution of the model allows a correspondingly high resolution analysis of the temporal correlations between evaporation and external factors limiting the flux; an analysis of the distribution and seasonality of these correlations is also presented. Results underline the importance of the accurate estimation of the flux of wet canopy evaporation and the coupling between soil moisture and transpiration if we are to understand the dynamics and trends of evaporation over the complete globe. 
Table 2. Annual precipitation $(P)$, evaporation $(E)$ and water available for runoff $(P-E)$ divided by continents for the period $2003-2007$. The contribution of rainfall interception loss $(I)$ to $E$ is also presented.

\begin{tabular}{|c|c|c|c|c|c|c|c|c|c|c|}
\hline \multirow[t]{2}{*}{ Continent } & \multirow{2}{*}{$\begin{array}{r}P \\
\mathrm{~mm}\end{array}$} & \multicolumn{3}{|c|}{$E$} & \multicolumn{3}{|c|}{$P-E$} & \multicolumn{3}{|c|}{$I$} \\
\hline & & $\mathrm{mm}$ & $10^{3} \mathrm{~km}^{3}$ & $\% P$ & $\mathrm{~mm}$ & $10^{3} \mathrm{~km}^{3}$ & $\% P$ & $\mathrm{~mm}$ & $10^{3} \mathrm{~km}^{3}$ & $\% P$ \\
\hline Africa & 930 & 545 & 16.2 & 59 & 385 & 11.4 & 41 & 38 & 1.1 & 4 \\
\hline Antarctica & 199 & 21 & 0.3 & 11 & 177 & 2.5 & 89 & 0 & 0.0 & 0 \\
\hline Asia & 648 & 388 & 16.8 & 60 & 260 & 11.3 & 40 & 38 & 1.7 & 6 \\
\hline Europe & 638 & 369 & 3.5 & 58 & 269 & 2.6 & 42 & 54 & 0.5 & 9 \\
\hline N. America & 665 & 413 & 9.5 & 62 & 252 & 5.8 & 38 & 42 & 1.0 & 6 \\
\hline Oceania & 795 & 519 & 4.6 & 65 & 276 & 2.5 & 35 & 50 & 0.4 & 6 \\
\hline S. America & 1712 & 967 & 17.0 & 56 & 745 & 13.1 & 44 & 144 & 2.5 & 8 \\
\hline Total & 799 & 463 & 67.9 & 58 & 336 & 49.0 & 42 & 50 & 7.2 & 6 \\
\hline
\end{tabular}

\subsubsection{Overview of the global hydrological fluxes}

For a certain region, and over a sufficiently long period to allow the net change of water storage in the soil to be neglected, the land-incoming precipitation is either recycled back into the atmosphere through evaporation, or it drains into the water bodies in the region. Figure 4 presents a graphic overview of the latitudinal partitioning of precipitation according to GLEAM. Average annual volumes of the different hydrological fluxes are illustrated for the period 2003-2007. All the fluxes are larger close to the Equator due to the higher average incoming radiation, temperature and specific humidity.

Table 2 shows the volumes of total precipitation $(P)$, evaporation ( $E$ - which includes transpiration, soil evaporation, snow sublimation and interception loss) and water available for runoff $(P-E)$ for each continent. The right-hand columns present the contribution of tall vegetation rainfall interception $(I)$ to the long-term partitioning of $P$ into $E$ and $P-E$. The volume of annual global land-surface evaporation is estimated as $67.9 \times 10^{3} \mathrm{~km}^{3}$. Tall vegetation interception amounts to $11 \%$ of the continental evaporation or $6 \%$ of the continental precipitation. Fluxes are larger in South America due to the faster dynamics of the hydrological cycle over Amazonia which results from the majority of South America's land mass being located within the ITCZ; this is more easily recognised when the fluxes are expressed per unit area.

To better understand the role of $I$ in the partitioning of incoming precipitation over forested ecosystems, the landuse classification scheme of the International GeosphereBiosphere Programme (IGBP) is used in Table 3 to present the same hydrological fluxes allocated to biome types. Given that $I$ is calculated for the fraction of tall canopy within each pixel, it can still occur within pixels in which the dominant land use is not forest. Tropical forests contribute to $29 \%$ of the global land-surface evaporation and $57 \%$ of the global canopy interception loss. In these ecosystems, $20 \%$ of the evaporation corresponds to the flux of rainfall interception;

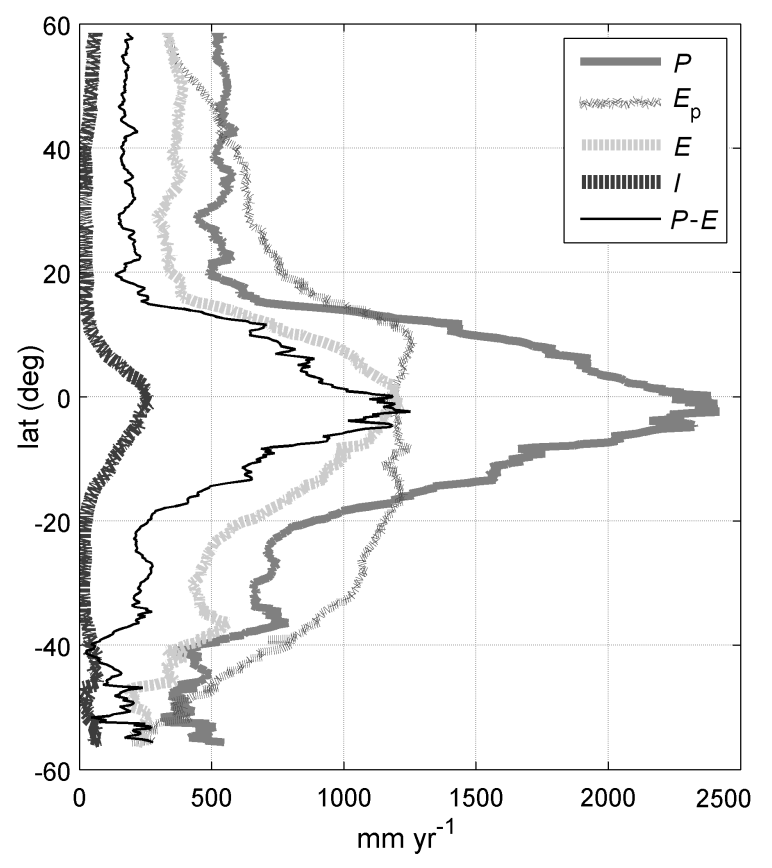

Fig. 4. Magnitude of the different hydrological fluxes as average along the latitudinal bands (modified from Fisher et al., 2008). The results correspond to the application of GLEAM for the period 2003-2007. $E_{\mathrm{p}}$ refers to potential evaporation.

this flux is equivalent to $22 \%$ of the water available for river discharge. At higher latitudes the relative contribution of interception loss to land-surface evaporation is also large. In temperate forests, the volume of $I$ is on average $13 \%$ of the incoming precipitation (19\% of evaporation).

\subsubsection{Spatial distribution of evaporation and its different components}

The ability of GLEAM to estimate the components of the evaporative flux in a separate manner is exploited to show the relative importance of each component over different 
Table 3. Annual precipitation $(P)$, evaporation $(E)$, water available for runoff $(P-E)$ and rainfall interception loss $(I)$ per biome type for 2003-2007.

\begin{tabular}{|c|c|c|c|c|c|c|c|c|c|c|}
\hline \multirow[t]{2}{*}{ Biome } & \multirow{2}{*}{$\begin{array}{r}P \\
\mathrm{~mm}\end{array}$} & \multicolumn{3}{|c|}{$E$} & \multicolumn{3}{|c|}{$P-E$} & \multicolumn{3}{|c|}{ I } \\
\hline & & $\mathrm{mm}$ & $10^{3} \mathrm{~km}^{3}$ & $\% P$ & $\mathrm{~mm}$ & $10^{3} \mathrm{~km}^{3}$ & $\% P$ & $\mathrm{~mm}$ & $10^{3} \mathrm{~km}^{3}$ & $\% P$ \\
\hline Tropical forest & 2250 & 1182 & 19.6 & 53 & 1068 & 17.7 & 47 & 232 & 3.8 & 10 \\
\hline Temperate forest & 718 & 512 & 4.7 & 71 & 207 & 1.9 & 29 & 95 & 0.9 & 13 \\
\hline Boreal forest & 594 & 372 & 2.9 & 63 & 222 & 1.7 & 37 & 79 & 0.6 & 13 \\
\hline Shrubland & 502 & 315 & 8.2 & 63 & 187 & 4.9 & 37 & 9 & 0.2 & 2 \\
\hline Savanna & 1339 & 806 & 14.7 & 60 & 533 & 9.7 & 40 & 51 & 0.9 & 4 \\
\hline Grassland & 689 & 462 & 4.2 & 67 & 227 & 2.1 & 33 & 15 & 0.1 & 2 \\
\hline Cropland & 878 & 542 & 10.7 & 62 & 336 & 6.6 & 38 & 31 & 0.6 & 4 \\
\hline Permanent snow & 225 & 27 & 0.4 & 12 & 198 & 3.3 & 88 & 0 & 0.0 & 0 \\
\hline Desert & 167 & 112 & 2.6 & 67 & 54 & 1.2 & 33 & 0 & 0.0 & 0 \\
\hline TOTAL & 799 & 463 & 67.9 & 58 & 336 & 49.0 & 42 & 50 & 7.2 & 6 \\
\hline
\end{tabular}

ecosystems. The global distribution of the average annual evaporation during the period 2003-2007 is presented in Fig. 5. The spatial distribution and latitudinal profile for the different components of evaporation is also shown (both in $\mathrm{mm} \mathrm{yr}^{-1}$ and in $\mathrm{km}^{3} \mathrm{yr}^{-1}$ ). Transpiration contributes to the majority of global land evaporation. It is the largest in the humid tropics due to the sufficient availability of soil moisture during the entire year and the dependency of transpiration on the incoming radiation. Overall, the contribution of canopy interception to the global volume of evaporation is larger than the contribution from bare soil evaporation and snow sublimation. Evaporation from bare soil is important in desert regions even though it only happens during (and shortly after) the sporadic rainfall events. Peaks of snow sublimation occur in the Himalayas where annual net radiation is higher than in other permanent snow-covered areas due to its location closer to the Equator.

Figure 6 illustrates the contribution to global land-surface evaporation from: (a) each continent, and (b) each biome type. It also shows the relative magnitude of the four constituents of the evaporative flux. As seen in Tables 2 and 3, the continent evaporating the largest volume of water is South America (25\%), followed by Asia (24.5\%) and Africa (23.5\%). $29 \%$ of world's evaporation occurs in tropical forests and $21 \%$ in savannas. The contribution from transpiration amounts to $80 \%$ of the total evaporative flux from land; $11 \%$ is interception loss, $7 \%$ bare soil evaporation and $2 \%$ to snow sublimation.

The seasonal distribution of the main inputs and outputs of the methodology is explored in Fig. 7. Global maps of $R_{n}, P$, $E, I$ and $P-E$ for 2003-2007 are presented as an average for two different periods: the months of June, July and August (JJA), and December, January and February (DJF). The global distributions of both $I$ and $P-E$ are dominated by the seasonal cycle of $P$. The observed patterns also indicate the lower importance of seasonal changes in $E$ - compared to changes in $P$ - in the availability of water for runoff at different times of the year. The seasonal distribution of $E$ is mainly dominated by the cycle of $R_{n}$ over most of the world (see also Sect. 4.2.2). The largest seasonal variations in $E$ are found in subtropical areas with sufficient input of $P$ during the summer period; in some of these regions the volume of $E$ in summer-time becomes almost one order of magnitude larger than during winter-time (see for instance Northern Australia, Southern Africa or the east coast of United States). In desert regions where rainfall events rarely happen (like central Australia or the Arabian Peninsula) the volumes of evaporation remain low during the entire year and the seasonal distribution of $E$ is independent of the cycle of $R_{n}$.

\subsubsection{Drivers of evaporation}

The main factors that limit land evaporation are the available energy and the volume of precipitation. The spatial and temporal distribution of these limiting factors, and the strength of the correlation of evaporation with one particular driver, can provide valuable information on the seasonal dynamics of evaporation in a particular area. Teuling et al. (2009) hypothesised that regional trends in land evaporation respond to trends in the limiting drivers. Only when we know to what extent a specific driver is controlling the evaporation process, known changes in that controlling factor may be translated into long-term changes in evaporation.

Here, the GLEAM-estimated relationship between land evaporation and its external drivers is analysed at a global scale. Figure 8 gives a global overview of such analysis for the period 2003-2007. This figure has been made using the technique by Teuling et al. (2010) for plots with bivariate colour maps. Figure 8a shows for JJA the global distribution of the correlation coefficient between daily time series of $E$ and $R_{n}$ and the correlation coefficient between $E$ and $\theta$ (volumetric water content for the whole root-zone). Figure $8 \mathrm{~b}$ shows the same inferences for the period DJF. Figure 8c,d 

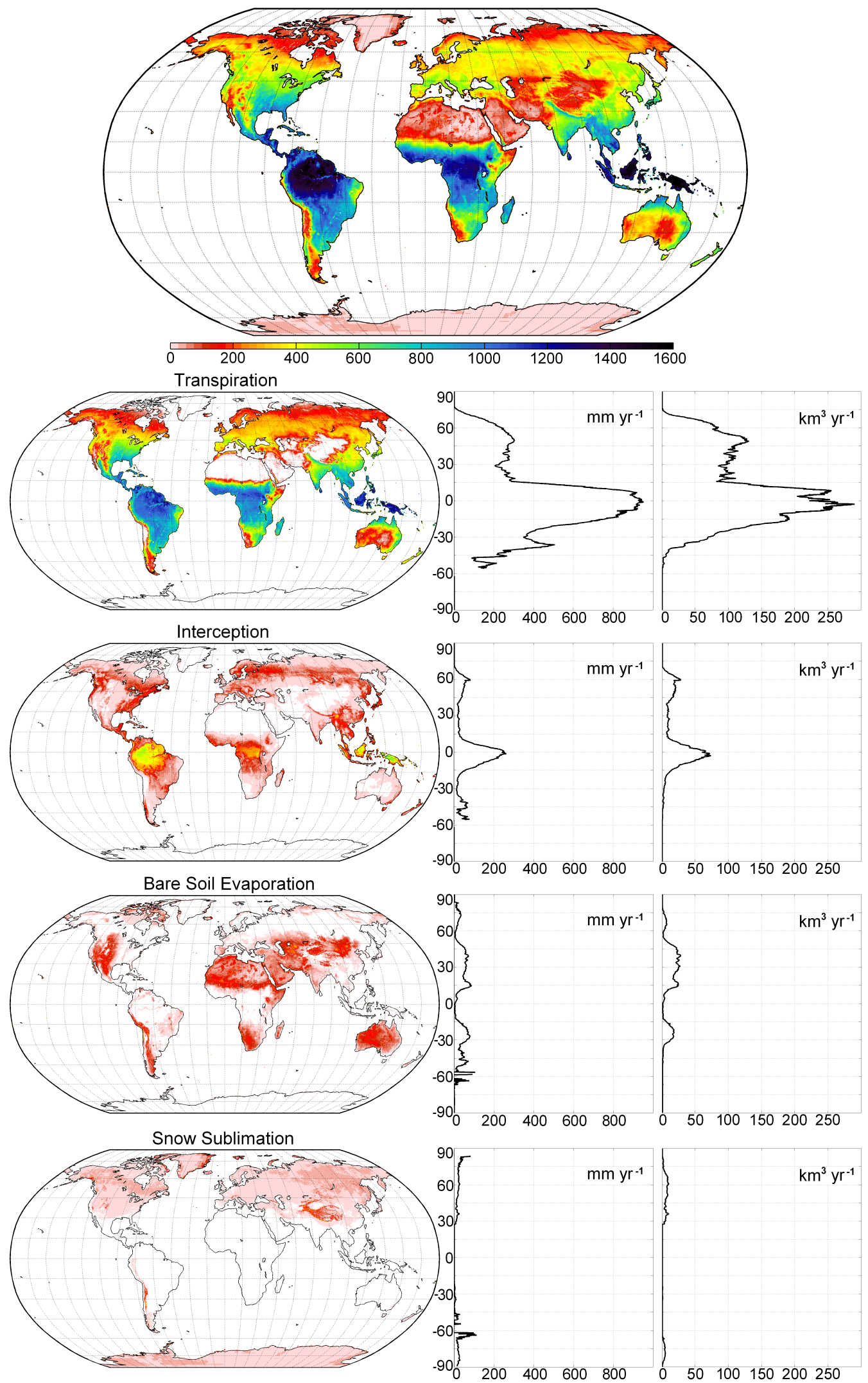

Fig. 5. Decomposition of 2003-2007 average annual evaporation (mm) into its contributing fluxes. The latitudinal profiles are shown in units of $\mathrm{mm} \mathrm{yr}^{-1}$ and $\mathrm{km}^{3} \mathrm{yr}^{-1}$. 


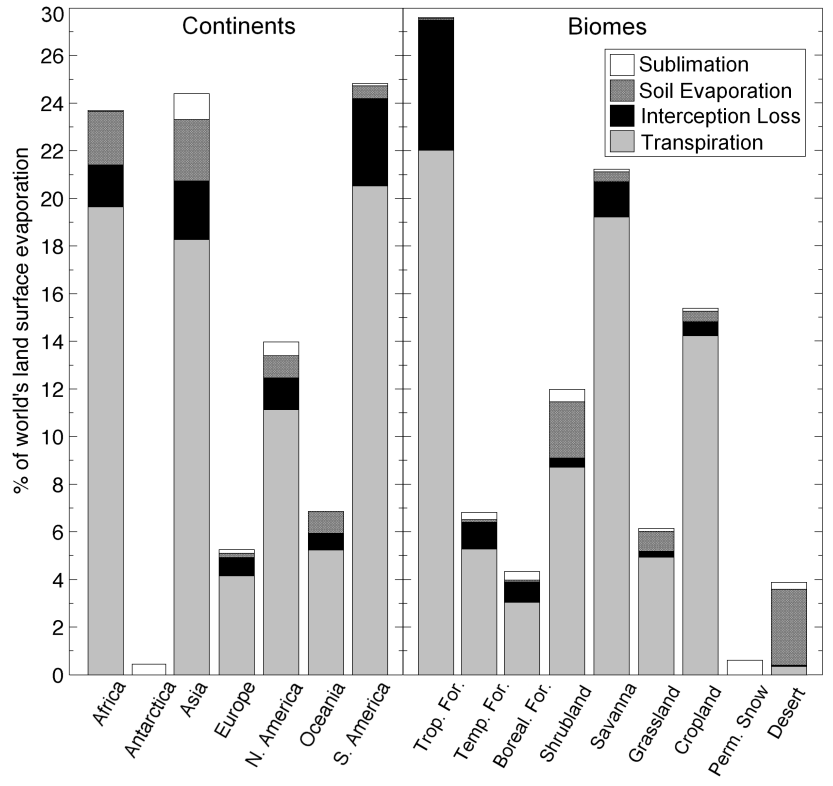

Fig. 6. Contribution to global land-surface evaporation (in \%) for each: (a) continent, and (b) biome type. The relative contribution of the constituents of evaporation is presented separately.

present the global distribution of the correlation between $E$ and $R_{n}$, and $E$ and $P$ for JJA and DJF, respectively.

The model predicts that most of the JJA daily variability of $E$ over Central Europe and North America can be explained by the dynamics in $R_{n}$ (see high correlation between $E$ and $R_{n}$ in Fig. 8a). In forested areas in boreal winter-time $P$ becomes important (see Fig. 8d) and the relation with $R_{n}$ is weaker. Despite the high correlation between $E$ and $P, E$ remains relatively uncorrelated with $\theta$; this suggests that the soil remains under no stress for transpiration. The component of forest evaporation that is affected by $P$ (and governing the dynamics of $E$ ) is therefore not the transpiration flux but the rainfall interception loss. For tropical rain forests, despite the fact that $R_{n}$ remains in general the largest controlling factor, $P$ is also identified as an important driver of evaporation in both seasons.

Areas presenting high correlations between $E$ and $\theta$ correspond mainly to arid and semi-arid regions, and especially during summer-time (see Fig. 8a and b). In these regions the correlation of $E$ with the time series of $P$ is lower than the correlation between $E$ and $\theta$; this is because soil moisture is a more direct indicator of plant water stress. The areas where soil moisture is likely to limit the evaporative flux can also be seen in Fig. 9. This figure presents the global average (2003-2007) distribution of the estimates of daily stress factor, $S-$ which equals $(E-I) / E_{p}$ (see Sect. 2.1). The left map represents the months of JJA; the right map shows DJF. GLEAM calculates $S$ at daily time-step based on estimates of soil moisture and vegetation optical depth (see Miralles et al., 2011). Values of $S=1$ correspond to areas where there is sufficient water to meet the atmospheric evaporative demand; values of $S=1$ are present in areas where the shortage of water restricts the actual rate of evaporation under its potential value. It can be seen that over the majority of the world's land surface, land conditions regulate to certain extent the flux of evaporation. In high latitudes the availability of water is generally sufficient to meet the atmospheric demand. Arid and semi-arid regions, however, remain under evaporative stress during almost the entire year. The seasonal spatial patterns of $S$ are strongly related to the seasonal distribution of $P$ (Fig. 7c and d) and the distribution of the correlation between $E$ and $\theta$ (Fig. 8a and b).

\section{Discussion}

The average annual land-surface evaporation estimated by GLEAM for the period 2003-2007 is $67.9 \times 10^{3} \mathrm{~km}^{3}$. This number is comparable to other estimates of average annual land evaporation - e.g. the $71 \times 10^{3} \mathrm{~km}^{3}$ found by Baumgartner and Reichel (1975) (see Dolman and Gash, $2010)$, the $65.5 \times 10^{3} \mathrm{~km}^{3}$ found by Oki and Kanae (2006), the $65 \times 10^{3} \mathrm{~km}^{3}$ reported by Jung et al. (2010) or the $65.8 \times 10^{3} \mathrm{~km}^{3}$ by Schlosser and Gao (2010). Lim and Roderick (2009) analysed the global partitioning of precipitation over land making use of the GCMs from the Intergovernmental Panel on Climate Change (IPCC) Fourth Assessment Report (AR4). Despite referring to a different period than the one presented here (2003-2007 versus 1970-1999) the volume of incoming precipitation is similar in both studies. While the ensemble of GCMs estimated that $70 \%$ of the global land precipitation was evaporated and $30 \%$ was available for runoff $(P-E)$, the global partitioning in GLEAM is somewhat different: $58 \%$ evaporation and $42 \%$ water available for runoff. Despite this difference the relative contribution from each continent to global $E$ and global $P-E$ agrees well in both studies. One exception is South America in which the GCMs estimated $51 \%$ less $P-E$ than GLEAM. It is worth mentioning that this dissimilarity responds mainly to the different volumes of precipitation and not of evaporation.

Results shown in Table 2 are also in good agreement with the average volumes of $P, E$ and $P-E$ reported for each continent by Sellers (1965) and Baumgartner and Reichel (1975) (see Peixoto and Oort, 1992). The GLEAMestimated fraction of $P$ that is evaporated over Africa (58\%) is however much lower than the $76 \%$ and $84 \%$ reported by Sellers (1965) and by Baumgartner and Reichel (1975) respectively. These differences come again from discrepancies in the volume of precipitation (and not evaporation). The low density of the rainfall observational network in Africa makes traditional gauge-based estimates of precipitation for this continent - like the ones by Sellers (1965) and Baumgartner and Reichel (1975) - highly uncertain (see Love et al., 2004). The use of satellite information in CMORPH reduces 

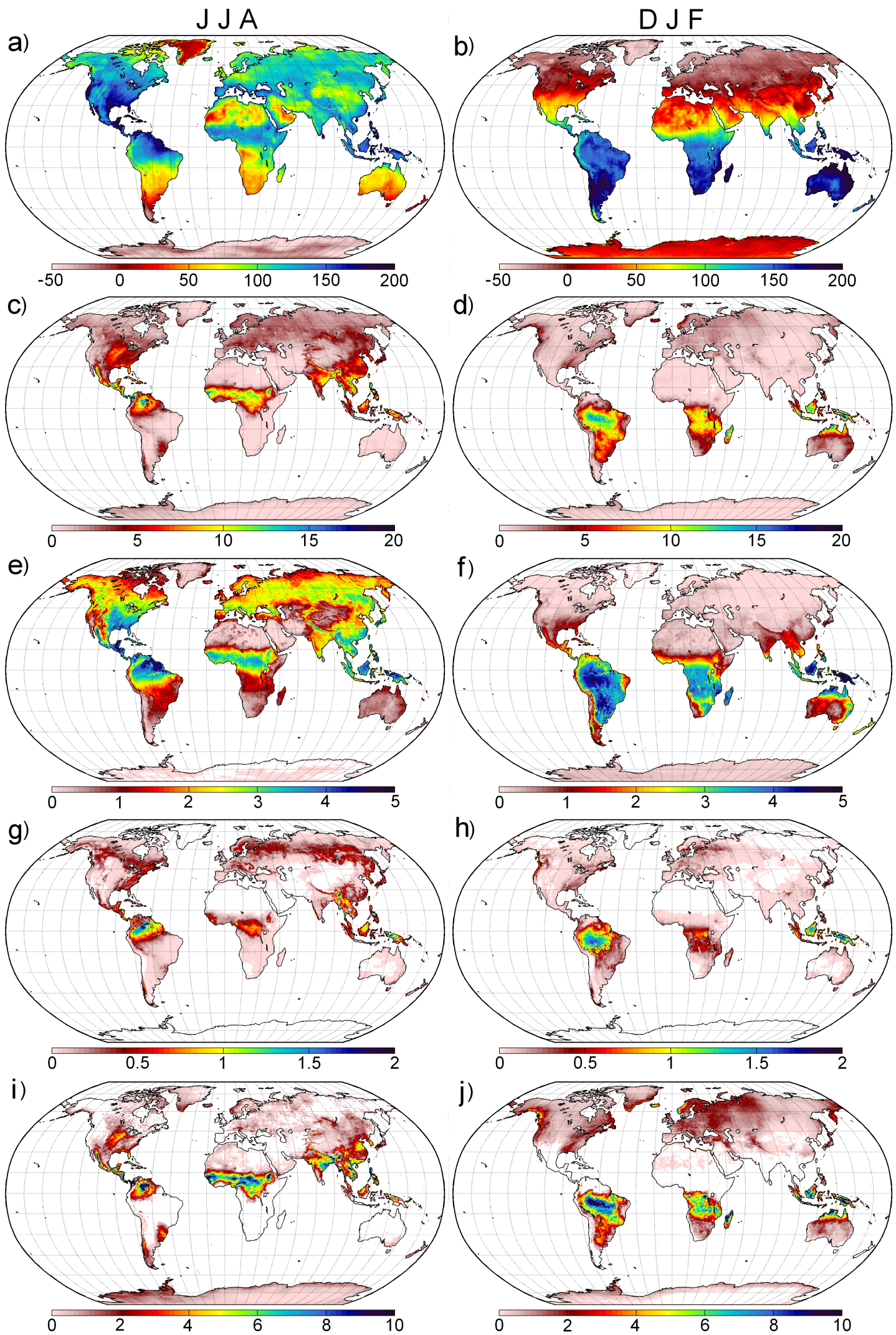

Fig. 7. Average fluxes for the period 2003-2007 separately presented for JJA (left panel) and DJF (right panel): (a) and (b) show the distribution of $R_{n},(\mathbf{c})$ and (d) represent $P,(\mathbf{e})$ and (f) are $E,(\mathbf{g})$ and (h) are $I$, and (i) and (j) present the estimated distribution of $P-E$. Units are mm day ${ }^{-1}$ except for $R_{n}$ which is presented in $\mathrm{W} \mathrm{m}^{-2}$. 

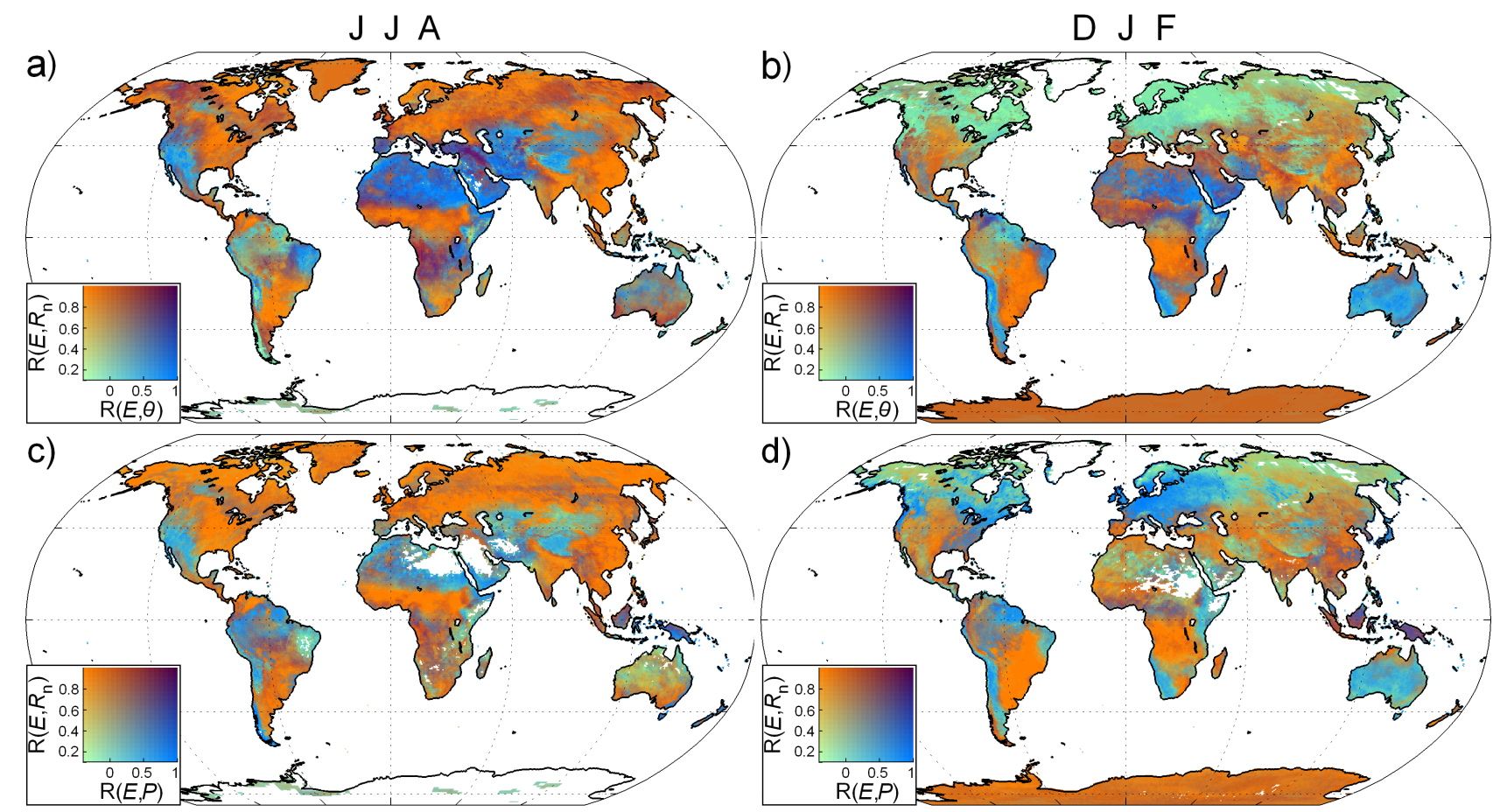

Fig. 8. The upper panel shows the estimated correlation $(R)$ of daily time series of $E$ with $R_{n}$ and $\theta$ for (a) JJA and (b) DJF. The bottom figures show the correlation of daily $E$ with $R_{n}$ and $P$ during (c) JJA and (d) DJF. All the results correspond to the period $2003-2007$.
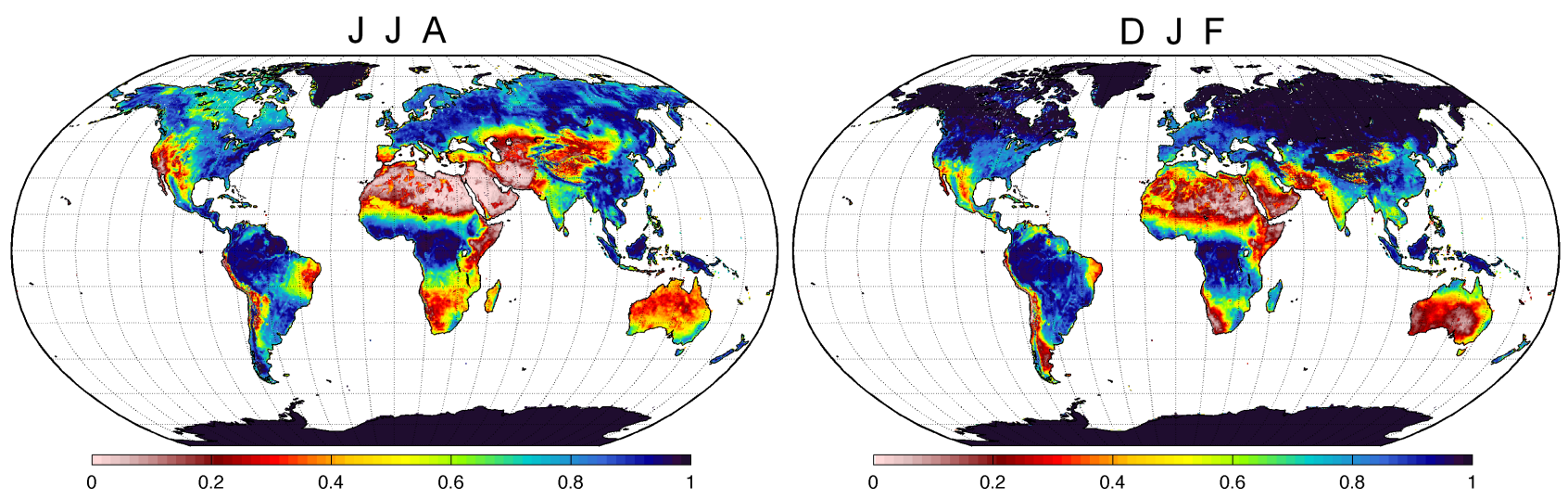

Fig. 9. Estimated stress factor $(S)$ as averaged for the months of JJA and DJF

this uncertainty and enhances the reliability of GLEAM estimates of $E$ and $P-E$ in areas of sparse observations like Africa.

Fisher et al. (2008) obtained similar results (both in absolute and in relative terms) to the ones presented in the latitudinal profile of annual fluxes shown in Fig. 4. Humid tropics show a value of land evaporation around $50 \%$ of the incoming precipitation, in accordance with the level of rainfall recycling in these areas reported by Salati and Vose (1984). This latitudinal profile is in agreement with the hypothesis that at high latitudes in winter-time, the flux of interception loss - dominated by the aerodynamic forces rather than by the available energy - can represent the main source of evaporation in forested regions. When considering interception loss, evaporation can reach and even exceed the available energy (Stewart, 1977) (see also the results in Fig. 7). The different bio-physical processes behind interception loss and transpiration make wet canopy evaporation more dependent on the volume and duration of rainfall and less on the net radiation (see Shuttleworth and Calder, 1979). Under low energy availability, rates of wet canopy evaporation can become several times higher than the rates of transpiration which would be occurring under dry conditions (see commentary by Gash and Shuttleworth, 2007). In the context of 
the Penman-Monteith equation, the aerodynamic term (and not the energy one) is responsible for the major part of the flux. This is the main reason why interception loss requires a separate estimation, and why PT energy-based approaches are not suitable for its estimation.

Traditionally, studies on evaporation drivers have been focused on net radiation and soil moisture (considered only as the link between precipitation and evaporation). However, an important component of the evaporative flux from forests, canopy-intercepted rainfall, will not be directly affected by the soil moisture dynamics. Moreover, as stated above, the flux of evaporated water from wet canopies is relatively independent from the net radiation. Teuling et al. (2009) analysed in detail the drivers of the evaporative flux over Europe and North America focusing on net radiation and precipitation, but considering the latter only as a surrogate for soil moisture. Their results were extensively validated using FLUXNET data but rain-days were not included in this validation and therefore the role of interception could not be identified. The daily frequency and separate estimation of interception within GLEAM allows a detailed study of these interactions. However, while Teuling et al. (2009) compared independent estimates, in the study presented in Sect. 4.2.3 the estimates of $E$ are dependent on the values of $P, R_{n}$ and $\theta$, and therefore the results rely on the sensitivity of GLEAM $E$ to these variables. Consequently this study merely aims to understand how GLEAM reproduces interactions between land and atmosphere and how it estimates the relative importance of the evaporation drivers in different regions in the world.

Figure $8 \mathrm{a}$ and $\mathrm{c}$ shows how in summer-time and over Central Europe and North America, most of the variability of daily GLEAM estimates of $E$ can be explained by the dynamics in $R_{n}$. This is in agreement with Fig. 7a,b,e,f that illustrate how in the majority of the world's land surface the seasonality of $E$ follows closely the seasonality of the incoming solar energy. However, in forested regions and during winter-time the relationship is not obvious (see Fig. 8b). This low dependency between the time series of $E$ and the time series of $R_{n}$ is a response to the higher relative importance of $I$ as a component of $E$. This happens because of the low volumes of transpiration in winter-time. As can be appreciated from Fig. 8d, in forested regions under conditions of low incoming radiation, the model identifies the availability of water on the canopy (dominated by the volume of $P$ and its duration) as an important factor determining the dynamics of evaporation. The low correlations found with $\theta$ over the same areas, suggest that the correlation with $P$ is not a response to conditions of soil water deficit.

Trends in soil moisture can be responsible for the longterm changes in land evaporation; this happens over regions where water availability is the main control on the evaporation (see Teuling et al., 2009). Jung et al. (2010) analysed the results of their FLUXNET data-based approach (Jung et al., 2009) to reveal a positive trend in global land-surface evaporation from 1982 to 1997; from 1998 this trend slowed down, attributed to the decrease in soil moisture over the Southern Hemisphere. Dark blue-coloured regions in Fig. 8a and $b$ represent the areas where GLEAM identifies that a long-term decrease in soil moisture could potentially induce a negative trend in land evaporation. They are mainly arid and semi-arid regions, where the rate of actual evaporation rarely matches the potential rate (especially during summertime) and it is the availability of water in the soil that will determine the volume of daily evaporation (see also Fig. 9). This dependency on the soil moisture underlines the importance of correctly parameterising the soil water content and the stress conditions for those areas.

\section{Conclusions}

Large differences in the estimates of land-surface evaporation from the currently existing methodologies (Jiménez et al., 2011; Müller et al., 2011) indicate that land evaporation remains one of the most uncertain terms in the global water cycle. GLEAM is a new alternative to estimate global evaporation and its different components by combining satelliteobservable variables within a simple bio-physical approach. It aims to fill the gaps from previous satellite-based evaporation models acknowledging the importance of estimating interception loss through a widely-tested model (Gash's analytical model), and moderating PT estimates of latent heat flux by considering the soil water stress conditions over the entire root-zone. As with every model, GLEAM is a simplification of reality: results presented here are affected by the assumptions taken in the parameterisation of the bio-physical processes within the methodology. However, the constituent parts of GLEAM have been successfully validated by comparison with in situ data over different ecosystems and the error structure of the estimates has been analysed in detail; this sets the level of credibility of the results presented in this paper.

An average annual land evaporation of $67.9 \times 10^{3} \mathrm{~km}^{3}$ is estimated for the period 2003-2007, which represents $58 \%$ of the incoming precipitation. South America, Asia and Africa are found to contribute together to $73 \%$ of the evaporative flux over land, while only $5 \%$ occurs in Europe. Half of the world's land evaporation is originated in tropical forests and savannas. Transpiration contributes to $80 \%$ of global land-surface evaporation. Canopy interception loss is estimated as $11 \%$ and plays a major role in the long-term partition of rainfall and the volume of runoff generated in forested ecosystems. Precipitation is identified as an important factor driving evaporation in forest regions due to the effect of evaporation of canopy-intercepted rainfall. Soil moisture limited regions where trends on land evaporation are likely respond to trends in soil available water are located by the methodology. 
Ongoing activities include the application of GLEAM to develop a 24 year database (from 1984 to 2007), and an interproduct comparison with existing global fields of evaporation within the LandFlux-EVAL initiative of the GEWEX Radiation Panel (Jiménez et al., 2011; Müller et al., 2011). The applicability of triple collocation will be further explored using the longer record of evaporation; different sources of evaporation will be applied to test the sensitivity of the estimated errors to the potential dependency between GLEAM and Princeton University products. The dataset could additionally be used to investigate trends in land evaporation and their relation to ocean oscillations, the effects of landuse changes such as desertification or deforestation on the hydrological cycle, and the coupling between land and atmospheric processes.

All GLEAM products will become freely available through the web portal hosted at the VU University Amsterdam Geo-services website (http://geoservices.falw.vu.nl).

Acknowledgement. The work was undertaken as part of the European Union (FP6) funded Integrated Project called WATCH (Contract No. 036946). The data used in the validation of the $P-E$ estimates was provided by the Global Runoff Data Centre, 56068 Koblenz, Germany. We would like to thank A. J. Teuling for his feedback on the application of the technique explained in Teuling et al. (2010) and his valuable comments. We also thank C. Jiménez for his detailed review, and R. H. Reichle and J. Sheffield for providing the datasets used in the triple collocation study.

Edited by: B. van den Hurk

\section{References}

Baumgartner, A. and Reichel, E.: The World Water Balance: Mean Annual Global Continental and Maritime Precipitation, Evaporation and Runoff, Elsevier Scientific Publishing Company, Amsterdam, The Netherlands, Oxford, UK and New York, USA, 1975.

Blyth, E. M., Shuttleworth, W. J, and Harding, R. J.: Summary of the GEWEX International Symposium on Global Land-surface Evaporation and Climate, Hydrol. Process., 23, 3411-3412, 2009.

Bosilovich, M.: NASA's Modern Era Retrospective-analysis for Research and Applications: Integrating Earth Observations, EarthZine, E-Zine article, 2008.

Choudhury, B. J. and DiGirolamo, N. E.: A biophysical processbased estimate of global land surface evaporation using satellite and ancillary data; I. Model description and comparison with observations, J. Hydrol., 205, 164-185, 1998.

De Jeu, R. A. M., Wagner, W., Holmes, T. R. H., Dolman, A. J., van de Giesen, N. C., and Friesen, J.: Global soil moisture patterns observed by space borne microwave radiometers and scatterometers, Surv. Geophys., 29, 399-420, 2008.

Di Baldassarre, G. and Montanari, A.: Uncertainty in river discharge observations: a quantitative analysis, Hydrol. Earth Syst. Sci., 13, 913-921, doi:10.5194/hess-13-913-2009, 2009.

Dinku, T., Ceccato, P., Grover-Kopec, E., Lemma, M., Connor, S. J., and Ropelewski, C. F.: Validation of satellite rainfall products over East Africa's complex topography, Int. J. Remote Sens., 28, 1503-1526, doi:10.1080/01431160600954688, 2007.

Dirmeyer, P. A., Gao, X. A., Zhao, M., Guo, Z. C., Oki, T., and Hanasaki, N.: GSWP-2 Multimodel anlysis and implications for our perception of the land surface, B. Am. Meteorol. Soc., 87, 1381-1397, 2006.

Dolman, A. J. and De Jeu, R. A. M.: Evaporation in focus, Nat. Geosci., 3, 296, 2010.

Dolman, A. J. and Gash, J. H.: Evaporation in the global hydrological cycle, in: Treatise on Water Science, edited by: Wilderer, P., Treatise on Water Science, vol. 2, Academic Press, Oxford, 79-87, 2010.

Dorigo, W. A., Scipal, K., Parinussa, R. M., Liu, Y. Y., Wagner, W., de Jeu, R. A. M., and Naeimi, V.: Error characterisation of global active and passive microwave soil moisture datasets, Hydrol. Earth Syst. Sci., 14, 2605-2616, doi:10.5194/hess-142605-2010, 2010.

Ebert, E. E., Janowiak, J. E., and Kidd, C.: Comparison of nearreal time precipitation estimates from satellite observations and numerical models, B. Am. Meteorol. Soc., 88, 47-64, 2007.

Fisher, J. B., Tu, K. P., and Baldocchi, D. D.: Global estimates of the land-atmosphere water flux based on monthly AVHRR and ISLSCP-II data, validated at 16 FLUXNET sites, Remote Sens. Environ., 112, 901-919, 2008.

Gash, J. H.: An analytical model of rainfall interception by forests, Q. J. Roy. Meteorol. Soc., 105, 43-55, 1979.

Gash, J. H. and Shuttleworth, W. J.: Vegetation controls on evaporation - commentary, in: Benchmark Papers in Hydrology: Evaporation, edited by: Gash, J. H. and Shuttleworth, W. J., IAHS Press, Wallingford, 233-239, 2007.

Hirpa, F. A., Gebremichael, M., and Hopson, T.: Evaluation of high resolution satellite precipitation products over very complex terrain in Ethiopia, J. Appl. Meteorol. Clim., 49, 1044-1051, doi:10.1175/2009JAMC2298.1, 2009.

Huffman, G. J., Adler, R. F., Morrissey, M. M., Bolvin, D. T., Curtis, S., Joyce, R., McGavock, B., and Susskind, J.: Global precipitation at one-degree daily resolution from multisatellite observations, J. Hydrometeorol., 2, 36-50, 2001.

Jiménez, C., Prigent, C., and Aires, F.: Toward an estimation of global land surface heat fluxes from multisatellite observations, J. Geophys. Res.-Atmos., 114, D06305, doi:10.1029/2008JD011392, 2009.

Jiménez, C., Prigent, C., Müller, B., Seneviratne, S. I., McCabe, M. F., Wood, E. F., Rossow, W. B., Balsamo, G., Betts, A. K., Dirmeyer, P. A., Fisher, J. B., Jung, M., Kanamitsu, M., Reichle, R. H., Reichstein, M., Rodell, M., Sheffield, J., Ku, T., and Wang, K.: Global inter-comparison of 12 land surface heat flux estimates, J. Geophys. Res.-Atmos., 116, D02102, doi:10.1029/2010JD014545, 2011.

Joyce, R. J., Janowiak, J. E., Arkin, P. A., and Xie, P.: CMORPH: A method that produces global precipitation estimates from passive microwave and infrared data at high spatial and temporal resolution, J. Hydrometeorol., 5, 487-503, 2004.

Jung, M., Reichstein, M., and Bondeau, A.: Towards global empirical upscaling of FLUXNET eddy covariance observations: validation of a model tree ensemble approach using a biosphere model, Biogeosciences, 6, 2001-2013, doi:10.5194/bg-6-20012009, 2009. 
Jung, M., Reichstein, M., Ciais, P., Seneviratne, S., Sheffield, J., Goulden, M., Bonan, G., Cescatti, A., Chen, J., de Jeu, R., Dolman, A. J., Eugster, W., Gerten, D., Gianelle, D., Gobron, N., Heinke, J., Kimball, J., Law, B., Montagnani, L., $\mathrm{Mu}$, Q., Mueller, B., Oleson, K., Papale, D., Richardson, A., Roupsard, O., Running, S., Tomelleri, E., Viovy, N., Weber, U., Williams, C., Wood, E., Zaehle, S., and Zhang, K.: Recent decline in the global land evapotranspiration trend due to limited moisture supply, Nature, 467, 951-954, doi:10.1038/nature09396, 2010.

Lim, W. H. and Roderick, M. L.: An Atlas of the Global Water Cycle: Based on the IPCC AR4 models, ANU E Press, Canberra, 2009.

Lin, B., Stackhouse Jr., P. W., Minnis, P., Wielicki, B. A., Hu, Y., Sun, W., Fan, T.-F., and Hinkelman, L. M.: Assessment of global annual atmospheric energy balance from satellite observations, J. Geophys. Res., 113, D16114, doi:10.1029/2008JD009869, 2008.

Love, T. B., Kumar, V., Xie, P. and Thiaw, W.: A 20-year daily Africa precipitation climatology using satellite and gauge data. In Proceedings of the 84th AMS Annual Meeting, P5.4. Conference on Applied Climatology, Seattle, WA, 2004.

Miralles, D. G., Crow, W. T., and Cosh, M. H.: Estimating spatial sampling errors in coarse-scale soil moisture estimates derived from point-scale observations, J. Hydrometeorol., 11, 14231429, doi:10.1175/2010JHM1285.1, 2010a.

Miralles, D. G., Gash, J. H., Holmes, T. R. H., De Jeu, R. A. M., and Dolman, A. J.: Global canopy interception from satellite observations, J. Geophys. Res.-Atmos., 115, D16122, doi:10.1029/2009JD013530, 2010b.

Miralles, D. G., Holmes, T. R. H., De Jeu, R. A. M., Gash, J. H., Meesters, A. G. C. A., and Dolman, A. J.: Global land-surface evaporation estimated from satellite-based observations, Hydrol. Earth Syst. Sci., 15, 453-469, doi:10.5194/hess-15-453-2011, 2011.

Mu, Q., Heinsch, F. A., Zhao, M., and Running, S. W.: Development of a global evapotranspiration algorithm based on MODIS and global meteorology data, Remote Sens. Environ., 111, 519536, 2007.

Müller, B., Seneviratne, S. I., Jiménez, C., Corti, T., Hirschi, M., Balsamo, G., Ciais, P., Dirmeyer, P., Fisher, J. B., Guo, Z., Jung, M., Maignan, F., McCabe, M. F., Reichle, R., Reichstein, M., Rodell, M., Sheffield, J., Teuling, A. J., Wang, K., Wood, E. F., and Zhang, Y.: Evaluation of global observations-based evapotranspiration datasets and IPCC AR4 simulations, Geophys. Res. Lett., doi:10.1029/2010GL046230, in press, 2011.

Murphy, D. M. and Koop, T.: Review of the vapour pressures of ice and supercooled water for atmospheric applications, Q. J. Roy. Meteorol. Soc., 131, 1539-1565, 2005.

Oki, T. and Kanae, S: Global hydrological cycles and world water resources, Science, 313, 1068-1072, 2006.

Peixoto, J. P. and Oort, A. H.: Physics of Climate, American Institute of Physics, New York, USA, 172 pp., 1992.

Salati, E. and Vose, P. B.: Amazon Basin: a system in equilibrium, Science, 225, 129-138, 1984.

Schlosser, C. A. and Gao, X.: Assessing evapotranspiration estimates from the second Global Soil Wetness Project (GSWP-2) simulations, J. Hydrometeor, 11, 880-897, doi:10.1175/2010JHM1203.1, 2010.
Scipal, K., Holmes, T., de Jeu, R., Naeimi, V., and Wagner, W.: A possible solution for the problem of estimating the error structure of global soil moisture data sets, Geophys. Res. Lett., 35, L24403, doi:10.1029/2008g1035599, 2008.

Sellers W. D.: Physical Climatology, University of Chicago Press, Chicago, IL, USA, 1965.

Sheffield, J., Wood, E. F., and Munoz-Arriola, F.: Long-term regional estimates of evapotranspiration for Mexico based on downscaled ISCCP data, J. Hydrometeorol., 11, 253-275, 2010.

Shuttleworth, W. J. and Calder, I. R.: Has the Priestley-Taylor equation any relevance to forest evaporation?, J. Appl. Meteorol., 18, 639-646, 1979.

Stackhouse, P. W., Gupta, S. K., Cox, S. J., Mikovitz, J. C., Zhang, T., and Chiacchio ,M.: 12 year surface radiation budget data set GEWEX News, 14, 2004.

Stewart, J. B: Evaporation from the wet canopy of a pine forest, Water Resour. Res., 13, 915-921, 1977.

Stoffelen, A.: Toward the true near-surface wind speed: Error modeling and calibration using triple collocation, J. Geophys. Res., 103, 7755-7766, doi:10.1029/97jc03180, 1998.

Teuling, A. J., Hirschi, M., Ohmura, A., Wild, M., Reichstein, M., Ciais, P., Buchmann, N., Ammann, C., Montagnani, L., Richardson, A. D., Wohlfahrt, G., and Seneviratne, S. I.: A regional perspective on trends in continental evaporation, Geophys. Res. Lett., 36, L02404, doi:10.1029/2008GL036584, 2009.

Teuling, A. J., Stöckli, R., and Seneviratne, S. I.: Bivariate colour maps for visualizing climate data (short communication), Int. J. Climatol., doi:10.1002/joc.2153, in press, 2010.

Tian, Y., Peters-Lidard, C. D., Chaudhury, B. J., and Garcia, M.: Multitemporal analysis of TRMM-based satellite precipitation products for land data assimilation applications, J. Hydrometeorol., 8, 1165-1183, 2007.

Troy, T. J. and Wood, E. F.: Comparison and evaluation of gridded radiation products across northern Eurasia, Environ. Res. Lett., 4, 045008, doi:10.1088/1748-9326/4/4/045008, 2009.

Valente, F., David, J. S., and Gash, J. H.: Modelling interception loss for two sparse eucalypt and pine forests in Central Portugal using reformulated Rutter and Gash analytical models, J. Hydrol., 190, 141-162, 1997.

Zeweldi, D. A. and Gebremichael, M.: Evaluation of CMORPH precipitation products at fine space-time scales, J. Hydrometeorol., 10, 300-308, 2009.

Zhang, K., Kimball, J. S., Nemani, R. R., and Running, S. W.: A continuous satellite-derived global record of land surface evapotranspiration from 1983 to 2006, Water Resour. Res., 46, W09522, doi:10.1029/2009WR008800, 2010.

Zhang, Y., Rossow, W. B., Lacis, A. A., Oinas, V. and Mishchenko, M. I.: Calculation of radiative fluxes from the surface to top of atmosphere based on ISCCP and other global data sets: Refinements of the radiative transfer model and the input data, J. Geophys. Res., 109, D19105, doi:10.1029/2003JD004457, 2004.

Zhang, Y., Rossow, W. B., and Stackhouse Jr., P. W.: Comparison of different global information sources used in surface radiative flux calculation: Radiative properties of the surface, J. Geophys. Res., 112, D01102, doi:10.1029/2005JD007008, 2007. 